\title{
Development of UPS-SMES as a Protection From Momentary Voltage Drop
}

\author{
Toshiyuki Mito, Akifumi Kawagoe, Hirotaka Chikaraishi, Kagao Okumura, Ryo Abe, Tomosumi Baba, \\ Kenji Yamauchi, Mitsuhiro Yokota, Tsutomu Henmi, Kazutaka Seo, Kazuo Hayashi, Masataka Iwakuma, and \\ Fumio Sumiyoshi
}

\begin{abstract}
We have been developing the UPS-SMES as a protection from momentary voltage drop and power failure. The superconducting system is suitable as electric power storage for large energy extraction in a short time. The most important feature of superconducting coil system for the UPS-SMES is easy handling and maintenance-free operation. We have selected Low Temperature Superconducting (LTS) coils instead of High Temperature Superconducting (HTS) coils from the viewpoint of cost and performance. However, it is difficult for the conventional LTS coils to fulfill maintenance-free operation since the cooling methods are either pool boiling with liquid helium or forced flow of supercritical helium. Thus, a conduction cooled LTS pulse coil has been designed as a key component of the UPS-SMES. The development program of $1 \mathrm{MW}, 1 \mathrm{sec}$ UPS-SMES is explained.
\end{abstract}

Index Terms-Conduction cooled, momentary voltage drop, power failure, UPS SMES.

\section{INTRODUCTION}

$\mathbf{I}_{\mathrm{a}}^{\mathrm{N}}$ $\mathrm{N}$ INFORMATION machines and equipment, such as a computer, the uninterruptible power supply (UPS) is becoming indispensable for data protection. On the other hand, in industrial fabrication facilities such as a semiconductor chip production equipment or large-sized experimental facilities for big science such as a nuclear fusion experimental device, there is no effective protection for the momentary voltage drop and power failure due to their large electrical capacities. This leads to the serious damage for a yield fall of products or a discontinuation of important experiment. In general, most of troubles for the commercial electric power system are less than 1 second. Therefore, the UPS with a large capacity of MW and short time duration of 1 second is very useful not only for the above-mentioned applications but also for broad fields. We have been developing the UPS-SMES as a protection from momentary voltage drop and power failure. Five-year project to develop UPS-SMES is being started from 2002 fiscal year

Manuscript received October 20, 2003. This work is supported in part by the grant of NEDO.

T. Mito, H. Chikaraishi, T. Baba, K. Yamauchi, M. Yokota, and K. Seo are with the National Institute for Fusion Science, Toki, Gifu 509-5292, Japan (e-mail: mito@nifs.ac.jp).

A. Kawagoe and F. Sumiyoshi are with both Kagoshima University, Kagoshima 890-0065, Japan.

K. Okumura is with the Technova Inc., 13th Fl. Imperial Tower, Chiyoda-ku, Tokyo 100-0011, Japan.

R. Abe and K. Hayashi are with the IDX Company, DE Edison Bld., Higashigotanda, Shinagawa-ku, Tokyo 141-0022, Japan.

M. Iwakuma is Kyushu University, Higashi-ku, Fukuoka 812-8581, Japan.

T. Henmi is with the Graduate University for Advanced Studies, Toki, Gifu 509-5292, Japan.

Digital Object Identifier 10.1109/TASC.2004.830084 as one of the research promotion program of the New Energy and industrial technology Development Organization (NEDO). As the first step, we have been developing a $100 \mathrm{~kJ}$ class UPS-SMES in order to do a principle actual proof. Then we are planning to develop a $1 \mathrm{MW}, 1 \mathrm{sec}$ UPS-SMES. The design and development of the $100 \mathrm{~kJ}$ coil and the electrical circuits for the UPS-SMES are reported in the related papers [1] and [2], respectively. The design concept of a conduction cooled LTS pulse coil for $1 \mathrm{MW}, 1 \mathrm{sec}$ UPS-SMES are described in this paper.

\section{CONCEPT OF UPS-SMES}

\section{A. Basic Idea of UPS-SMES}

Fig. 1 shows a basic block diagram for UPS-SMES, which consists of an AC switch, an AC/DC converter, a superconducting (SC) coil system, a SMES control system and a compensable electric load. The AC switch disconnects the compensable electric load from the electric power system when a momentary voltage drop or a power failure occurs. The AC/DC converter discharges the SC coil system to compensate an electric power of the compensable electric load when the AC switch opens. The SC coil system is used as electric power storage which is suitable for large energy extraction in a short time. The SMES control system detects a momentary voltage drop and controls the $\mathrm{AC}$ switch and the $\mathrm{AC} / \mathrm{DC}$ converter.

\section{B. Selection of Superconducting Coil and Cooling System}

The comparison of superconductor for a SC coil system is listed in Table I [3]. Because NbTi is an alloy, the mechanical properties are excellent compared with $\mathrm{Nb}_{3} \mathrm{Sn}$ of a compound, or HTS of ceramics. Moreover, NbTi can obtain high critical current density by deposit processing. They are suitable for manufacturing a long superconducting wire industrially. A NbTi coil has advantages of low cost, easy handling, low AC loss and high commercial productivity, which make up for disadvantages of low critical temperature and a large coil size caused by the low thermal margin in conduction cooled operation. $\mathrm{A} \mathrm{Nb}_{3} \mathrm{Sn}$ coil could improve the demerit of a NbTi coil. However, it has the demerit of high cost and difficult handling due to the heat treatment of making $\mathrm{Nb}_{3} \mathrm{Sn}$ compound. A HTS coil is attractive for the future use; however, it can not be selected now due to the low cost performance. We have selected a $\mathrm{NbTi}$ coil as an adequate solution considering the practical use of UPS-SMES. 


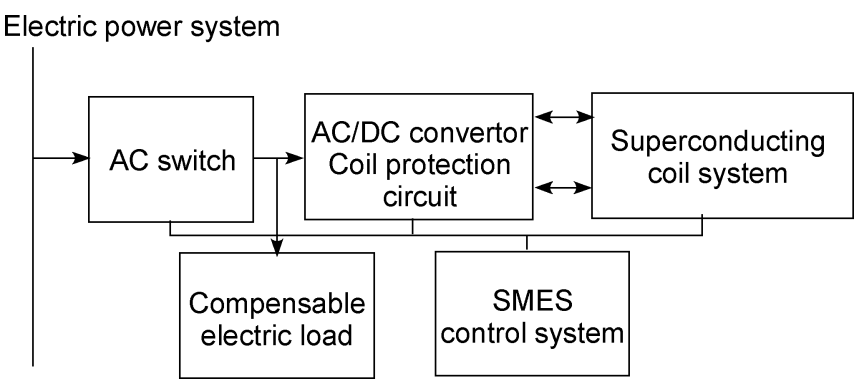

Fig. 1. Block diagram for UPS-SMES.

TABLE I

COMPARISON OF SUPERCONDUCTOR FOR PULSE COIL

\begin{tabular}{lccc}
\hline \hline \multirow{2}{*}{ Superconductor } & \multicolumn{2}{c}{ LTS } & HTS \\
\hline Cost & $\mathrm{NbTi}$ & $\mathrm{Nb}_{3} \mathrm{Sn}$ & $\mathrm{C}$ \\
Handling & $\mathrm{A}$ & $\mathrm{B}$ & $\mathrm{B}$ \\
AC loss & $\mathrm{A}$ & $\mathrm{B}$ & $\mathrm{C}$ \\
Commercial & $\mathrm{A}$ & $\mathrm{B}+$ & $\mathrm{C}$ \\
productivity & $\mathrm{A}$ & $\mathrm{A}-$ & $\mathrm{B}(\mathrm{Bi} 2223: 110 \mathrm{~K})$ \\
Critical temperature & $\mathrm{C}(9.1 \mathrm{~K})$ & $\mathrm{B}(18.3 \mathrm{~K})$ & $\mathrm{B}$ \\
Coil size & $\mathrm{C}$ & $\mathrm{A}$ & $\mathrm{B}-$ \\
\hline Total & $\mathrm{A}$ & $\mathrm{A}-$ & \\
\hline \hline
\end{tabular}

A: excellent, B: average, $\mathrm{C}$ : inferior

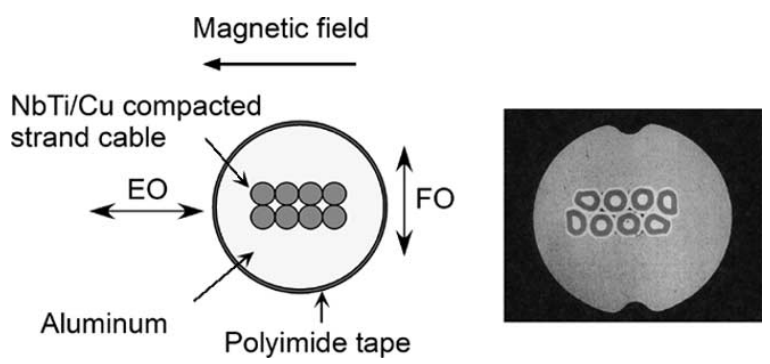

Fig. 2. Cross sectional view and photograph of SC conductor. AC loss is the minimum when the changing magnetic field is applied to EO orientation.

The SC coils for UPS-SMES are required to do pulse operation. The LTS pulse coils are usually cooled with pool boiling of the liquid helium (LHe) or forced flow of the supercritical helium (SHe). The pool boiling of LHe is widely used from the large scale application of superconducting magnet to the small experimental device. However, the handling of LHe needs technical knowledge and the unsuitable handling becomes a cause of failure. Furthermore, the LHe pool-boiling system becomes dangerous when the liquid helium evaporated rapidly due to a certain accident such as vacuum failure of cryostat. The forced flow of SHe is used for the large scale system such as a fusion experimental apparatus. Since it needs a special refrigerator with a circulation system of SHe, it is not suitable for UPS-SMES which requires easy handling. The conduction cooling has become popular as a cooling method for the cryocooler cooled LTS magnet. However, the application of the cryocooler cooled LTS magnet has been restricted only for DC use because of temperature rise accompanying AC loss. The merits and demerits of each cooling system are summarized in Table II. The most important features of SC coil system for
TABLE II

COMPARISON OF COOLING SYSTEM OF SC PULSE COILS

\begin{tabular}{lccc}
\hline \hline Cooling system & $\begin{array}{c}\text { Conduction } \\
\text { cooling }\end{array}$ & $\begin{array}{l}\text { Pool-boiling } \\
\text { of LHe }\end{array}$ & $\begin{array}{c}\text { Forced-flow } \\
\text { cooling of SHe }\end{array}$ \\
\hline Easy maintenance & $\mathrm{A}$ & $\mathrm{B}$ & $\mathrm{C}$ \\
Easy operation & $\mathrm{A}$ & $\mathrm{B}$ & $\mathrm{C}$ \\
Reliability & $\mathrm{A}$ & $\mathrm{B}$ & $\mathrm{B}$ \\
Safety & $\mathrm{A}$ & $\mathrm{C}$ & $\mathrm{B}$ \\
Cost of cryogenic & $\mathrm{A}$ & $\mathrm{A}$ & $\mathrm{C}$ \\
system & $\mathrm{C}$ & $\mathrm{B}$ & $\mathrm{A}$ \\
Cooling efficiency & $\mathrm{C}$ & $\mathrm{A}$ & $\mathrm{B}$ \\
Coil size & $\mathrm{C}$ & $\mathrm{A}$ & $\mathrm{A}$ \\
Coil stability & $\mathrm{A}$ & $\mathrm{B}+$ & $\mathrm{B}-$ \\
\hline Total & & &
\end{tabular}

A: excellent, B: average, C: inferior

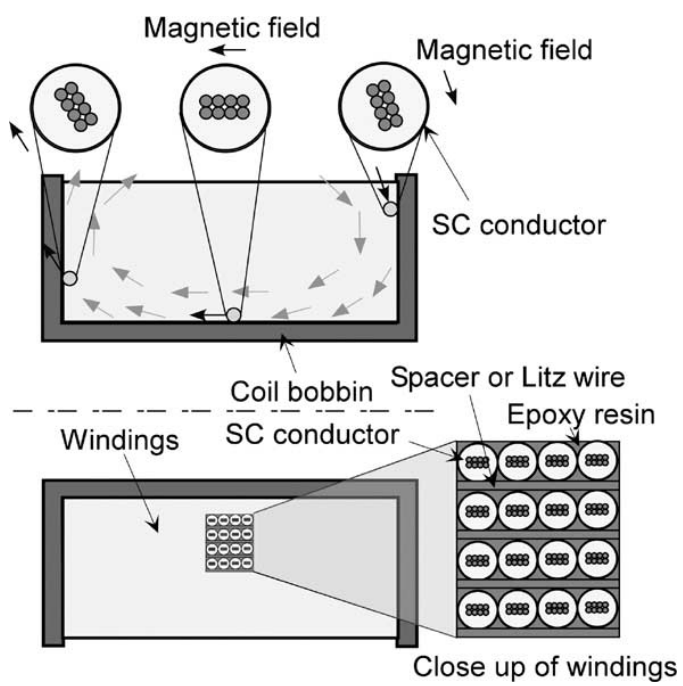

Fig. 3. Twist winding of conduction cooled pulse coil.

the UPS-SMES are easy handling, maintenance-free, high reliability and safe. We have selected the conduction cooling system as a most reliable and safety cooling scheme for the UPS-SMES which will be installed in a closed room.

\section{Development of the Superconducting Conductor}

The reduction of AC loss and high stability are required simultaneously for the SC conductor of the UPS-SMES. We have developed the SC conductor with the cross section shown in Fig. 2 and the specification listed in Table III.

A NbTi/Cu compacted strand cable, which is extruded with an ordinal aluminum (Al-1197), is designed to minimize the coupling loss when the changing magnetic field is applied to the edge-on orientation of the compacted strand cable (EO orientation). The AC loss of the conductor was measured with a short sample. The coupling time constant of EO orientation $\mathrm{n} \tau_{\mathrm{EO}}$ is $10 \mathrm{msec}$, although the coupling time constant of the face-on orientation of the compacted cable (FO orientation) $\mathrm{n} \tau_{\mathrm{FO}}$ is $82 \mathrm{msec}$ [4]. Aluminum is adapted not for a stabilizer but for a supporting structure of the twist winding to arrange the face side of the compacted cable parallel to the magnetic field orientation in the coil as shown in Fig. 3. The aluminum is also necessary as a heat sink to reduce temperature rise during pulse operation. 
TABLE III

SPECIFICATIONS OF A SUPERCONDUCTING CONDUCTOR

\begin{tabular}{ll}
\hline \hline Conductor type & $\begin{array}{l}\text { Aluminum coated NbTi/Cu compacted } \\
\text { strand cable }\end{array}$ \\
Conductor diameter & $5.8 \mathrm{~mm}$ \\
Cross section shape & Round with two grooves \\
Operational current & $1000 \mathrm{~A}$ \\
Critical current & $3740 \mathrm{~A} \mathrm{@} 5 \mathrm{~T}, 4.2 \mathrm{~K}$ \\
Insulation & $25 \mu \mathrm{m}$ thick $\times 15 \mathrm{~mm}$ wide \\
Outer diameter with insulation & Half wrap winding of Polyimide tape \\
Tensile strength & $5.9 \mathrm{~mm}$ \\
$0.2 \%$ Yield strength & $96 \mathrm{MPa}$ \\
Weight & $49 \mathrm{Mpa}$ \\
Coupling time constant of AC & $94.3 \mathrm{~kg} / \mathrm{km}$ \\
loss & $\mathrm{n} \tau_{\mathrm{FO}}: 82 \mathrm{msec}$ for face-on orientation \\
Compacted strand cable & $\mathrm{n} \tau_{\mathrm{EO}}: 10 \mathrm{msec}$ for edge-on orientation \\
$\quad$ Number of strands & 8 \\
$\quad$ Strand diameter & $0.823 \mathrm{~mm}$ \\
Dimension & $1.55 \times 3.36 \mathrm{~mm}$ \\
Aluminum coating & $\mathrm{Al}-1197$ \\
$\quad$ Material & 9.85 \\
$\quad$ RRR &
\end{tabular}

\section{Design Concept of A Conduction CoOled Pulse CoIL}

\section{A. Optimum Magnetic Field}

Fig. 4 shows a typical operational status of the 1 MJ SC coil for the UPS-SMES during the compensation of $1 \mathrm{sec}$ power failure. The coil current reduces as $1 / \sqrt{2}$ from $1000 \mathrm{~A}$ to $707 \mathrm{~A}$ in $1 \mathrm{sec}$, while the stored energy reduces as $1 / 2$ from $1 \mathrm{MJ}$ to $0.5 \mathrm{MJ}$ per one coil. After the quick discharge of $1 \mathrm{sec}$, the coil is charged up to the nominal current of $1000 \mathrm{~A}$ with slow ramp speed.

The fixed parameter of the SC coil for the UPS-SMES is the stored energy. We can select freely its magnetic field shape and strength. However, there is a limit coming from temperature rise of the $\mathrm{SC}$ conductor due to $\mathrm{AC}$ loss during pulse operation. Fig. 5 shows the allowable magnetic field of the conductor under $1 \mathrm{sec}$ pulse operation.

The critical current of the conductor $I_{c}$ under the magnetic field $\mathrm{B}$ and the temperature $\mathrm{T}$ is expressed empirically with the following equations [5]:

$$
\begin{aligned}
I_{c}(B, T) & =\alpha(T) B^{\gamma-1}\left(1-\frac{B}{B_{c 2}(T)}\right)^{\delta} \\
\alpha(T) & =\alpha\left(T_{0}\right)\left(\frac{T_{c 0}-T}{T_{c 0}-T_{0}}\right) \\
B_{c 2}(T) & =B_{c 2}(0)\left[1-\left(\frac{T}{T_{c 0}}\right)^{2}\right]
\end{aligned}
$$

where $\mathrm{B}_{\mathrm{c} 2}(\mathrm{~T})$ is the upper critical magnetic flux density at the temperature $\mathrm{T}, \alpha(\mathrm{T})$ is a function corresponding to the temperature dependence of the critical current, $\mathrm{T}_{\mathrm{c} 0}$ is the critical temperature at 0 field, $\gamma$ and $\delta$ are constant parameters for the magnetic field dependence of the critical current. For a NbTi conductor, it is usually obtained that $\gamma=0.5, \delta=1, \mathrm{~T}_{\mathrm{c} 0}=9.08 \mathrm{~K}$ and $\mathrm{B}_{\mathrm{c} 2}(0)=15$ T. $\alpha\left(\mathrm{T}_{0}\right)$ is fixed as 14,580 from the measured data of the critical current at $\mathrm{T}_{0}=4.2 \mathrm{~K}$.

Then the current sharing temperature at the beginning of the discharge process $\mathrm{T}_{\mathrm{s}_{-} \text {biginning, }}$, which indicates the upper limit

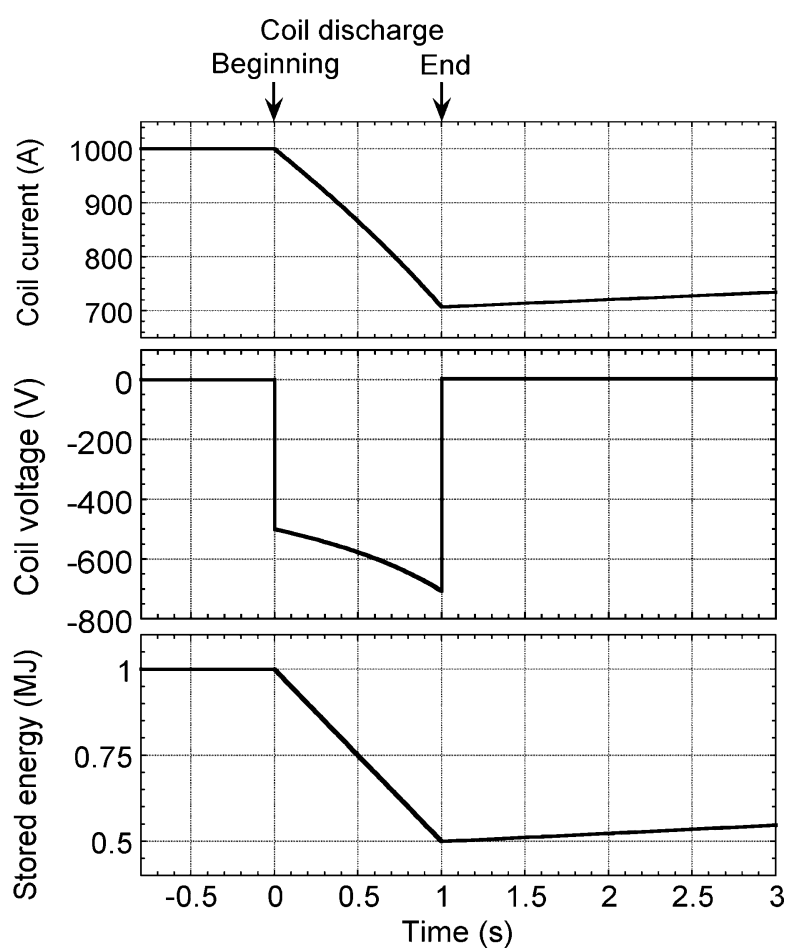

Fig. 4. Operational status of $1 \mathrm{MJ}$ pulse coil during the compensation.

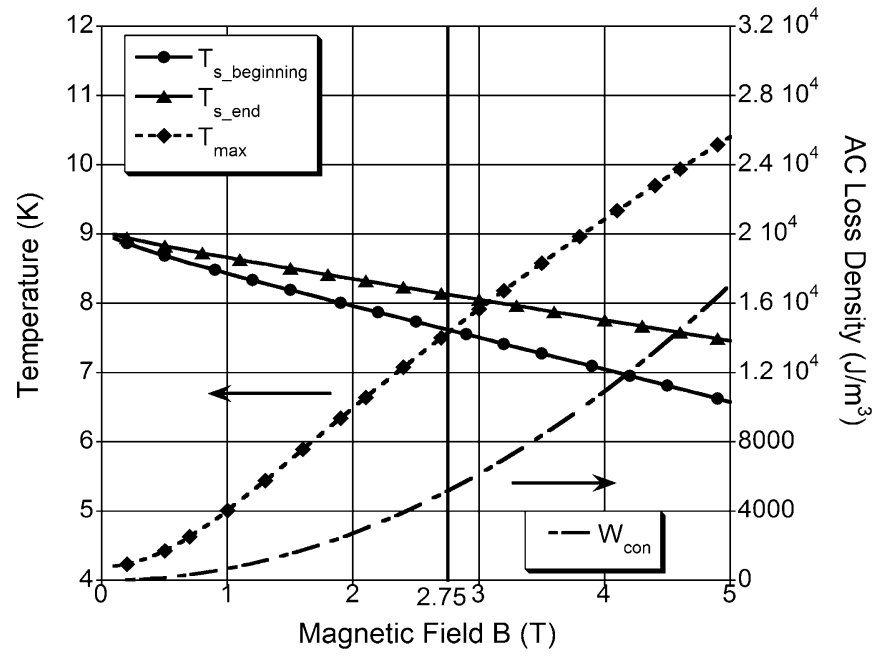

Fig. 5. Allowable magnetic field for the conductor under $1 \mathrm{sec}$ pulse operation Where $T_{\text {s_beginning }}$ is the current sharing temperature at $1000 \mathrm{~A}$ (beginning of the discharge process), $\mathrm{T}_{\mathrm{s}_{-} \text {end }}$ is the current sharing temperature at $707 \mathrm{~A}$ (end of the discharge process), as a function of the magnetic field. $\mathrm{W}_{\mathrm{con}}$ is the $\mathrm{AC}$ loss density of the conductor after $1 \mathrm{sec}$ pulse operation. $\mathrm{T}_{\max }$ is the maximum temperature of the conductor due to the AC loss assuming adiabatic condition.

of the coil operating temperature, is calculated as the temperature when $I_{c}\left(B, T_{\text {s_beginning }}\right)=1000 \mathrm{~A}$ using the software Mathcad. The current sharing temperature at the end of the discharge $\mathrm{T}_{\mathrm{S}_{-} \text {end }}$ is also calculated as the temperature when

$$
I_{c}\left(\frac{B}{\sqrt{2}}, T_{s_{-} \text {end }}\right)=707 \mathrm{~A} .
$$

Assuming that the magnetic field B is applied to the edge-on (EO) orientation of the compacted strand cable inside the conductor (the low AC loss orientation), the coupling loss density 


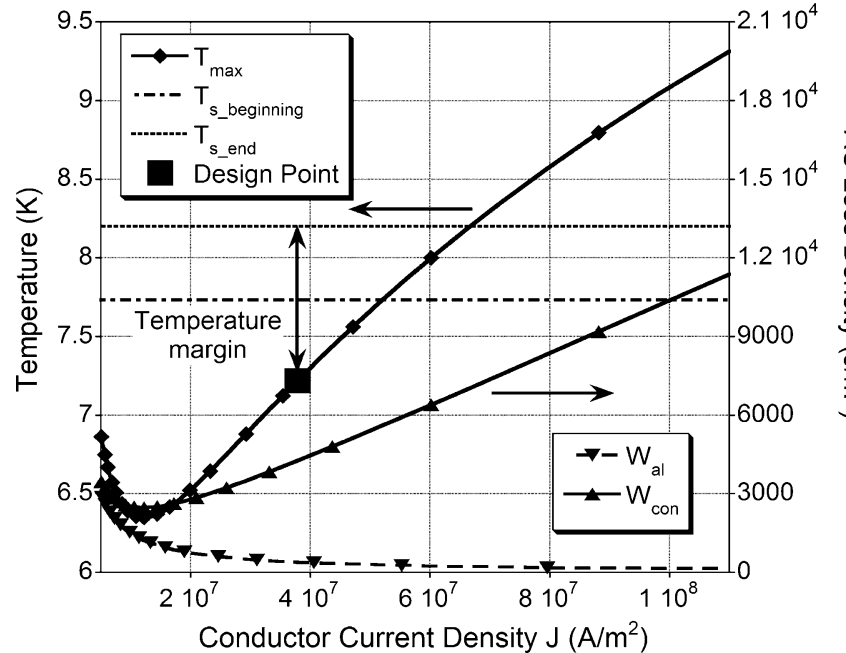

Fig. 6. Temperature margin vs. conductor current density. Wcon is the total AC loss density and Wal is the eddy current loss at the aluminum during $1 \mathrm{sec}$ pulse operation from the magnetic field of $2.5 \mathrm{~T}$ assuming adiabatic condition. Tmax, Ts_biginning, Ts_end are the same meanings as in Fig. 5.

of the conductor $\mathrm{W}_{\text {con }}(\mathrm{B})$ after $1 \mathrm{sec}$ pulse operation is calculated as a function of the magnetic field as follows:

$$
W_{\text {con }}(B)=\frac{n \tau_{E O}}{\mu_{0}}\left[B\left(1-\frac{1}{\sqrt{2}}\right)\right]^{2}
$$

where $\mathrm{n} \tau_{\mathrm{EO}}$ is the coupling time constant when the changing magnetic field is applied to the EO orientation, $\mu_{0}$ is the permeability of vacuum. Neglecting the hysteresis loss, which is smaller than the coupling loss in this operating condition, the maximum temperature of the conductor $\mathrm{T}_{\max }$ due to the $\mathrm{AC}$ loss is calculated assuming adiabatic condition.

From Fig. 5, the magnetic field is restricted under $2.75 \mathrm{~T}$ in order to satisfy the condition that the maximum temperature of the conductor $\mathrm{T}_{\max }$ is less than the current sharing temperatures ( $\mathrm{T}_{\mathrm{s} \_ \text {beginning }}$ and $\mathrm{T}_{\mathrm{S} \_ \text {end }}$ ). We decide the maximum magnetic field in the coil as $2.5 \mathrm{~T}$ considering a temperature margin.

\section{B. Optimum Current Density}

The current density of the conductor is $37.8 \mathrm{~A} / \mathrm{mm}^{2}$. It is relatively low value even through the maximum magnetic field is restricted to $2.5 \mathrm{~T}$. However, the low current density is necessary to satisfy the adequate temperature margin.

Fig. 6 shows the temperature margin vs. conductor current density. The conductor current density is changed with the aluminum diameter under the condition that the cross section of $\mathrm{NbTi} / \mathrm{Cu}$ compacted strand cable is fixed. The AC loss of the conductor $\mathrm{W}_{\text {con }}$ is calculated as the sum of the coupling current loss of the compacted strand cable and the eddy current loss in aluminum during $1 \mathrm{sec}$ pulse operation from the beginning magnetic field of $2.5 \mathrm{~T}$. Then the maximum temperature of the conductor $\mathrm{T}_{\max }$ due to the AC loss is calculated assuming adiabatic condition. $\mathrm{T}_{\mathrm{S} \_ \text {beginning }}$ and $\mathrm{T}_{\mathrm{S} \_ \text {end }}$ show the current sharing temperatures at the beginning of discharge $(1000 \mathrm{~A}$, $2.5 \mathrm{~T}$ ) and the end of the discharge (707 A, $1.77 \mathrm{~T})$, respectively.

The maximum temperature with the current density of $37.8 \mathrm{~A} / \mathrm{mm}^{2}$ is $7.2 \mathrm{~K}$ after $1 \mathrm{sec}$ pulse operation. The current

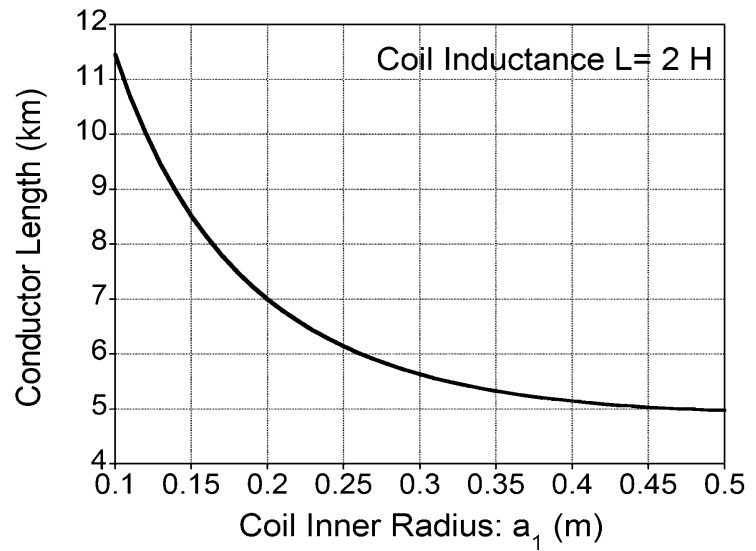

Fig. 7. Required conductor length vs. coil inner radius under the condition of the constant coil inductance of $2 \mathrm{H}$.

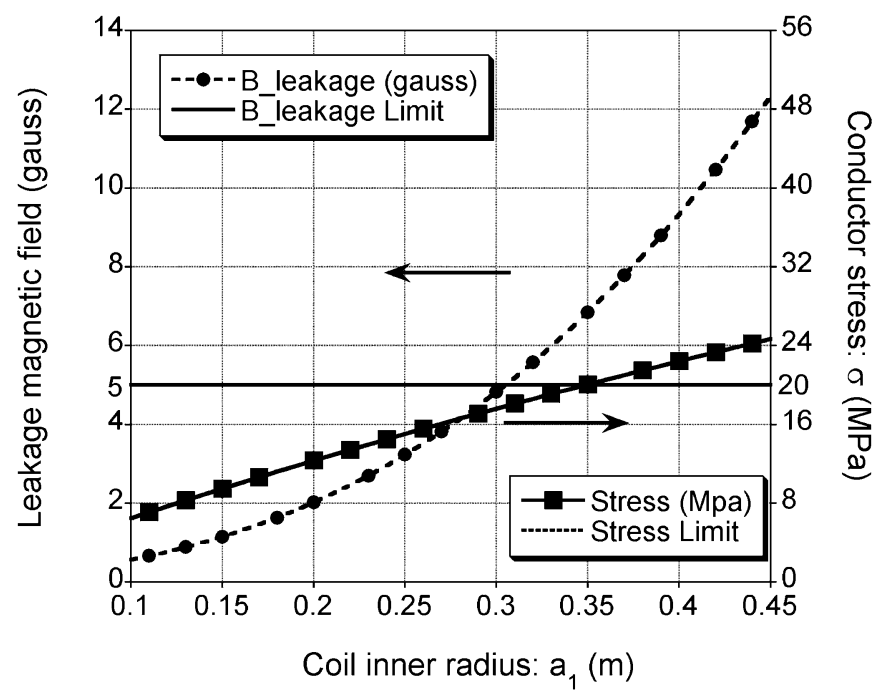

Fig. 8. Leakage magnetic field and conductor stress vs. coil inner radius.

sharing temperature at $707 \mathrm{~A}$ (end of discharge) is $8.2 \mathrm{~K}$. Therefore the temperature margin is $1.0 \mathrm{~K}$.

In Fig. 6, $\mathrm{W}_{\mathrm{al}}$ shows the eddy current loss of aluminum, which becomes larger at low current density region because of the increase in cross-section area of the aluminum part. However, the eddy current loss of the aluminum at design current density is negligible comparing to the coupling current loss of the compacted strand cable because of low residual resistivity ratio $(\mathrm{RRR}=9.85)$ of the aluminum. In this $\mathrm{SC}$ conductor, the aluminum part is very effective to increase the temperature margin without increasing the AC loss.

\section{Leakage Magnetic Field and Mechanical Strength}

The inductance and magnetic stored energy of the coil become larger as increasing the coil inner radius under the fixed condition of conductor length. It means that the large inner diameter and short axial length coil is better to reduce the length of conductor under the fixed inductance. Fig. 7 shows a calculated result of the conductor length which is required to wind a coil with the constant inductance of $2 \mathrm{H}$ as a function of the coil inner radius. However, the coil inner radius is restricted from the limits of leakage magnetic field and conductor stress. 
TABLE IV

SPECIFICATIONS OF A 1 MJ PUlse COIL

\begin{tabular}{lc}
\hline \hline Cooling method & $\begin{array}{c}\text { Conduction cooling with a } \\
\text { cryocooler }\end{array}$ \\
Dimension of the windings & $0.300 \mathrm{~m}$ \\
$\quad$ Inner radius: a1 & $0.402 \mathrm{~m}$ \\
Outer radius: a2 & $1.098 \mathrm{~m}$ \\
Length: 2L & 183 \\
Number of turns per 1 layer & 14 \\
Number of layers & $5.65 \mathrm{~km}$ \\
Length of conductor & $2.00 \mathrm{H}$ \\
Inductance & $2.48 \mathrm{~T}$ \\
Maximum magnetic field in coil & $1 \mathrm{MJ}$ \\
Magnetic stored energy & $1000 \mathrm{~A}$ \\
Start operating current & $707 \mathrm{~A}$ \\
Stop current after 1 sec discharge & $500 \mathrm{~kJ}$ \\
Discharge energy per one coil & $4.2 \mathrm{~K}$ \\
Initial operating temperature &
\end{tabular}

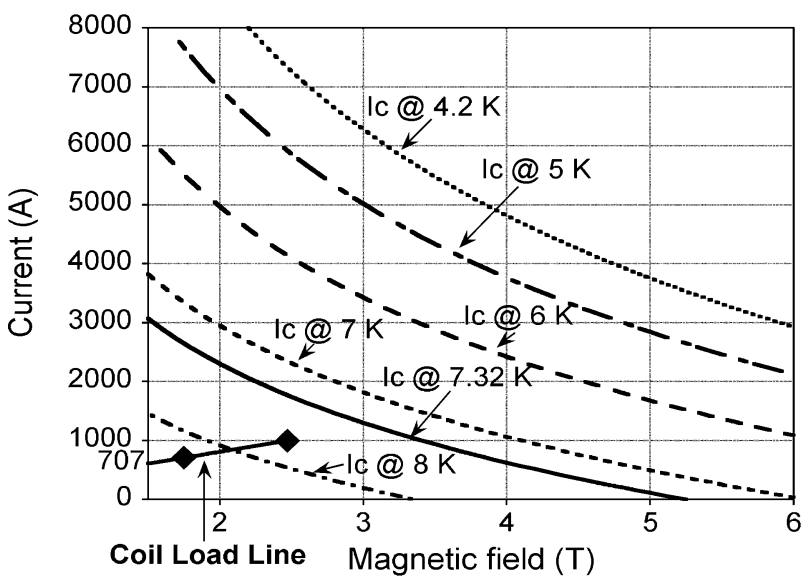

Fig. 9. Load line of the optimized $1 \mathrm{MJ}$ pulse coil.

Fig. 8 shows the leakage magnetic field and the conductor stress as a function of the coil inner radius. The leakage magnetic field is calculated at $5 \mathrm{~m}$ distance from the center with two coils configuration for $1 \mathrm{MJ}, 1 \mathrm{sec}$ UPS-SMES, in which two coils are arranged in parallel and magnetized in opposite direction. The layer number of the coil windings is fixed to 14 and the length of coil is varied under the condition of the constant inductance of $2 \mathrm{H}$. The coil inner radius should be less than $0.3 \mathrm{~m}$ due to the limit of the leakage magnetic field of 5 gauss at $5 \mathrm{~m}$ apart from the center. The coil inner radius is also restricted less than $0.35 \mathrm{~m}$ from the stress limit of the conductor $<20 \mathrm{MPa}$.

\section{Design OF 1 MJ Pulse CoIL System}

The optimized design specifications of the $1 \mathrm{MJ}$ pulse coil are listed in Table IV. Two $1 \mathrm{MJ}$ coils are necessary for a $1 \mathrm{MJ}$, $1 \mathrm{sec}$ UPS-SMES, in which two coils are arranged in parallel and magnetized in opposite direction. Fig. 9 shows the load line of the coil. The coil has large stability margin at $4.2 \mathrm{~K}$ operation as compared with the critical current of $4.2 \mathrm{~K}$. However, the margin reduces according to the temperature rise and becomes adequate when the coil temperature rises to $7.32 \mathrm{~K}$ after $1 \mathrm{sec}$ discharge operation as calculated in Table V and Fig. 10(a).
TABLE $\mathrm{V}$

COMParison BETweEn Twist Winding CoIL and Flat Winding CoIL

\begin{tabular}{lrr}
\hline \hline Winding method & Twist winding coil & Flat winding coil \\
\hline $\begin{array}{c}\text { Maximum temperature after } \\
\text { 1 sec discharge }\end{array}$ & $7.32 \mathrm{~K}$ & $9.19 \mathrm{~K}$ \\
$\begin{array}{c}\text { Position of max. temp. } \\
\text { Magnetic field at max. temp. } \\
\text { point after 1 sec discharge } \\
\text { (before discharge) }\end{array}$ & 1 layer, 92 turn & 6 layer, 1 turn \\
$\begin{array}{c}\text { Coil current after 1 sec } \\
\text { discharge (before discharge) }\end{array}$ & 707 A (1000 A) & $\leftarrow$ \\
$\begin{array}{c}\text { Current sharing temp:Ts after } \\
1 \text { sec discharge (707 A) }\end{array}$ & $8.21 \mathrm{~K} @ 1.76 \mathrm{~T}$ & $8.48 \mathrm{~K} @ 1.12 \mathrm{~T}(1.59 \mathrm{~T})$ \\
$\begin{array}{c}\text { Critical current at } \\
\text { max. temp. point }\end{array}$ & $2643 \mathrm{~A} @ 7.32 \mathrm{~K}$ & quench $($ over Ts) \\
$\begin{array}{c}\text { Maximum AC loss density } \\
\text { Total AC loss }\end{array}$ & $4.51 \mathrm{~kJ} / \mathrm{m}^{3}$ & $10.81 \mathrm{~kJ} / \mathrm{m}^{3}$ \\
Coupling loss & $204 \mathrm{~J}$ & $349 \mathrm{~J}$ \\
Hysteresis loss & $174 \mathrm{~J}$ & $319 \mathrm{~J}$ \\
\hline \hline
\end{tabular}

a)
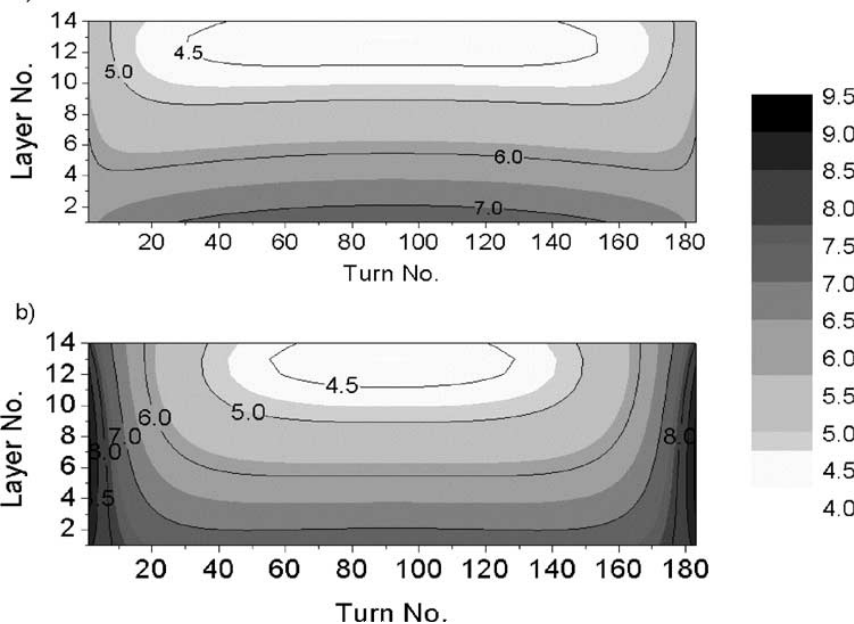
9.0 8.5 7.5 7.0

Fig. 10. Temperature rises of the twist winding coil and the flat winding. a) Tmax of $1 \mathrm{MJ}$ twist winding coil; b) Tmax of $1 \mathrm{MJ}$ flat winding coil.

The comparison of the twist winding coil and flat winding coil are listed in Table V. The contour maps of temperature rise after $1 \mathrm{sec}$ discharge are shown in Fig. 10. The twist winding coil is wound controlling the twist angle of the conductor so as to arrange the conductor EO orientation and the magnetic field orientation in the coil. The flat winding coil is wound without twisting of the conductor.

The AC loss of each turn in the coil windings is calculated as the sum of the coupling loss and the hysteresis loss of the conductor. The hysteresis loss is took into account because it can not be negligible compared with the coupling loss at the low magnetic field and the high critical current region in the coil. Then the distribution of the temperature rises in the coil due to the AC loss is calculated assuming adiabatic condition.

The maximum temperature in the twist winding coil after $1 \mathrm{sec}$ discharge is $7.32 \mathrm{~K}$, whereas the current sharing temperature is $8.21 \mathrm{~K}$. Therefore, the twist winding coil can be operated within the temperature margin of $0.9 \mathrm{~K}$. However, the maximum temperature of the flat winding coil after $1 \mathrm{sec}$ discharge is $9.19 \mathrm{~K}$, which exceeds the current sharing temperature of $8.48 \mathrm{~K}$, and the coil quenches. 


\section{SUMmary}

We have been developing $1 \mathrm{MW}, 1 \mathrm{sec}$ UPS-SMES as the five years project from 2002. The conduction cooled LTS pulse coil has been designed as a key component of this UPS-SMES. The design optimization of $1 \mathrm{MJ}$ conduction cooled pulse coil has been done as a base on the measured AC loss data of the manufactured SC conductor. The new twist winding method is adapted to the coil, which can reduce the AC loss and enables stable operation of the coil within the temperature margin. We have developed the special winding machine for the twist winding and have been constructing $100 \mathrm{~kJ}$ coil to do a principle actual proof. We are planning to construct a $1 \mathrm{MW}, 1 \mathrm{sec}$
UPS-SMES and to perform the long-term field test in NIFS as the final stage of the project.

\section{REFERENCES}

[1] A. Kawagoe et al., Development of Conduction Cooled LTS Pulse Coils for $100 \mathrm{~kJ}$ Class UPS-SMES as a Protection From Momentary Voltage Drop.

[2] H. Chikaraishi et al., Development of Power Converter for SMES Designed to Protect From Momentary Voltage Drop.

[3] K. Osamura, Superconducting Materials. Tokyo: Sangyo Tosyo, 2000.

[4] A. Kawagoe, F. Sumiyoshi, T. Mito, and T. Kawashima, "A new winding method to reduce AC losses in stable LTS pulse coils," IEEE Trans. Appl. Superconnd., vol. 13, no. 2, pp. 2404-2407, June 2003.

[5] K. Funaki and F. Sumiyoshi, Multifilament Wire and Conductor. Tokyo: Sangyo Tosyo, 1995, (in Japanese). 